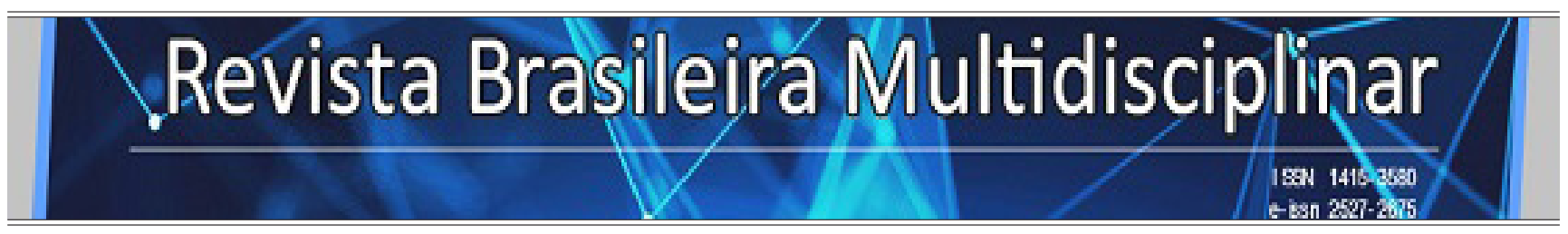

http://revistarebram.com/index.php/revistauniara

\title{
Sunomono de Pepino Japonês (Cucumis sativus) e do Pseudofruto de Caju (Anacardium occidentale)
}

Neide Kazue Sakugawa Shinohara*; Luciano Canadas da Silva ${ }^{\star *}$; Rosely Godoi da Silva**; Masayoshi Matsumoto ${ }^{\star \star \star}$.

* Docente dos Cursos de Engenharia Ambiental e Gastronomia na Universidade Federal Rural de Pernambuco.

**Pós-Graduação com Ênfase em Cozinha Oriental e Cozinha das Américas na Faculdade Metropolitana da Grande Recife.

*** Docente do Curso de Tecnologia em Gastronomia na Faculdade Metropolitana da Grande Recife.

${ }^{* *}$ Autor para correspondência e-mail: neideshinohara@gmail.com

\section{Palavras-chave}

Curcubitácea

Cajueiro

Culinária Japonesa

\section{KEYWORDS}

Cucumis sativus $\mathrm{L}$

Cashew Tree

Japanese Cuisine
RESUMO: O sunomono, conhecida técnica culinária na conservação de alimentos no vinagre, é uma prática antiga e bastante empregada na cultura japonesa, agregando características sensoriais apreciáveis e prolongamento da vida útil das hortaliças. O objetivo da pesquisa foi confeccionar sunomono de pepino e do pseudofruto de caju, alimentos muito apreciados no nordeste brasileiro. Foram realizados ensaios químicos para avaliação nutricional e microbiológica para comprovação de alimento seguro, atendendo legislação vigente no Brasil. Não foi detectado a presença de Escherichia coli, Staphylococcus coagulase positiva ou Salmonella spp. A determinação da composição centesimal de ambos os sunomono informam que o consumo deve ser realizado com cautela, porque o valor calórico e o percentual de carboidratos quando comparado com cada hortaliça in natura, apresentaram concentrações superiores, decorrente da incorporação de sacarose na preparação culinária. Entretanto, é importante observar que foram preservados as concentrações de proteínas e cinzas nas preparações finais em relação as in natura. Portanto, o sunomono se mostra como alternativa culinária viável para preservar hortaliças perecíveis e sazonais, importante grupo alimentar na dieta humana.

\begin{abstract}
Japanese Cucumber (Cucumis sativus) and Cashew Pseudofruit (Anacardium OCCIDENTALE) SUNOMONOS

Sunomono, a well-known culinary technique in the preservation of food in vinegar, is an ancient practice and widely used in Japanese culture, adding sensory characteristics and prolonging the useful life of vegetables. The objective of the research was to make cucumber and cashew pseudofruit sunomonos, foods that are much appreciated in northeastern Brazil. Chemical tests were carried out for nutritional and microbiological evaluation to assure the safety food, in compliance with current legislation in Brazil. The presence of Escherichia coli, Staphylococcus coagulase positive or Salmonella spp was not detected. The determination of the proximate composition of both sunomonos informs that the consumption must be carried out with caution, because the caloric value and the percentage of carbohydrates when compared with each vegetable in natura, presented higher concentrations, due to the incorporation of sucrose in the culinary preparation. However, it is important to note that the concentrations of protein and ash in the final preparations were preserved when compared to those in natura. Therefore, sunomono is a viable culinary alternative to preserve perishable and seasonal vegetables, an important food group in the human diet.
\end{abstract}




\section{INTRODUÇÃo}

A cultura alimentar asiática pode ser difícil de ser abraçada por outras etnias culinárias, devido a seu simbolismo quase místico em louvor ao natural. Todavia, o talento da cozinha japonesa preza a simplicidade, a combinação de sabores com a qualidade in natura dos ingredientes, sendo cada prato uma manifestação do amor pela natureza que os japoneses contemplam como algo precioso e fundamental, a ser observado na alimentação diária (RIBEIRO, MATSUMOTO, 2009; TAN, 2005).

$\mathrm{Na}$ alimentação japonesa é essencial apreciar o sabor, cor, aroma e textura das hortaliças frescas ou levar esses alimentos a cocção por menor tempo possível. Essa forma de consumo, caracteriza a alimentação vegetariana e tem na religião budista seu principal pilar, preceito religioso que condena a matança de animais e consequente roubo da vida (FUKUOKA, 2008; KAZUKO, 2010; FURLAN et al., 2020). Diante dessa proibição religiosa e cultural, houve a necessidade por parte dos japoneses inovar nas técnicas culinárias frente a diferentes fontes de origem vegetal, para melhor preservação dos nutrientes e características sensoriais desses alimentos, principalmente os sazonais.

Dentre as culturas que contribuíram para a formação da cultura alimentar mundial, temos a Washoku, uma prática alimentar e social japonesa, baseado em um conjunto de habilidades e conhecimento dos alimentos, práticas e tradições relacionadas à produção, processamento, preparação e consumo de alimentos. Está associado a um espírito essencial de respeito a sazonalidade, ao uso sustentável dos recursos naturais, em comunhão com todos da sociedade, envolvendo familiares, professores, instrutores de culinária e produtores rurais. A prática Washoku, desde 2013 consta na lista de representantes do patrimônio cultural imaterial da humanidade (UNESCO, 2019).

Dentre as hortaliças de grande consumo mundial temos a família das curcubitáceas, como representantes estão o pepino, abóbora e melancia. Trouxe grande contribuição à nutrição e o prazer da gula. No caso do pepino, foi domesticado por volta de 1500 a.C e na atualidade é a segunda curcubitácea mais consumida na alimentação humana no mundo. Cultura de verão da América do Norte, chamada de squash - "coisa verde que se come crua", como de clima quente, é prejudicado se permanecer durante muito tempo sob refrigeração, demandando cuidado no tempo de armazenamento (McGEE, 2011; REIS et al., 2006). No Brasil a região sudeste é responsável com cerca de $50 \%$ da produção nacional da cultura do pepino, alimento de grande importância social e econômica, por gerar empregos diretos e indiretos, desde o cultivo, distribuição e comercialização (CARVALHO et al., 2013).

Outra olerícola importante é o cajueiro, frutífera que cresce em solos arenosos de baixa fertilidade, nativa do litoral nordestino e parte da região norte brasileira (FREIRE et al., 2017; GOMES, 2012; MATOS, QUEIROZ, 2009; OLIVEIRA et al., 2018). Cultivo agrícola de elevada importância socioeconômica, emprega grande contingente de pessoas e participa expressivamente das divisas na exportação brasileira (OLIVEIRA et al., 2018; YOKOMIZO et al., 2019). O pedúnculo ou pseudofruto de caju tem menor emprego industrial, entretanto são suculentos, de sabor doce e amplamente consumido in natura, na forma de sucos, refrigerantes e doces industrializados. O pseudofruto quando maduro exala um aroma agradável e específico, encontrada nas cores amarelo, alaranjado, vermelha ou combinação dessas cores, aspectos sensoriais apreciáveis para amplo uso na culinária (PHILIPPI, 2014).

Uma forma de preparação da culinária japonesa e conservação de hortaliças, é o Sunomono, uma palavra derivada do ideograma japonês, que significa "su" (vinagre) e "mono" (qualquer alimento). Portanto, podemos traduzir como qualquer alimento conservado em vinagre (RIBEIRO, MATSUMOTO, 2009). De forma geral, o sunomono comercializado nos restaurantes brasileiros é o de pepino, bastante apreciado nos restaurantes especializados japoneses. A proposta dessa pesquisa foi o de elaborar sunomono de pepino e do pseudofruto do caju, comparando a composição centesimal, perfil bacteriológico e percentual de perdas nas hortaliças em ambas as preparações. 


\section{MATERIAL E MÉTODOS}

As amostras de pepino japonês e de pseudofruto de caju foram adquiridos no Centro de Abastecimento e Logística de Pernambuco (Ceasa/PE). Imediatamente após a aquisição, os alimentos foram levadas a um restaurante especializado em culinária japonesa, para confecção do sunomono de ambos os vegetais.

Os produtos in natura foram pesados, descascados, novamente pesados (cálculo de perdas) e higienizados. O procedimento de higienização foi colocar as hortaliças em contato com solução clorada de 200ppm (p/p) por 15 minutos. Após esse período com o sanitizante foi realizado o enxague em água potável e depois drenado em peneira por 15 minutos, posteriormente depositado em papel toalha por mais 30 minutos antes da confecção do sunomono. Essa etapa de sanitização visa cumprir procedimentos higiênicos e atender normas sanitárias, para garantir uma produção de alimento seguro (ABERC, 2015; BRASIL. 2019a; BRASIL, 2019b).

No Quadro 1, consta a ficha técnica da confecção de sunomono de pepino e pseudofruto de caju, com a descrição e gramatura dos ingredientes; tempo de preparo, peso da porção em gramas e forma de preparação.

Quadro 1 - Ficha técnica de sunomono do pepino e pseudofruto do caju.

\begin{tabular}{|l|l|}
\hline \multirow{2}{*}{ Sunomono de pepino e caju } & Tempo de preparo: 40 minutos \\
\cline { 2 - 2 } & Peso da porção: $100 \mathrm{~g}$ \\
\hline Ingredientes & Peso líquido \\
\hline 1. Pepino japonês & $608 \mathrm{~g}$ \\
\hline 2. Pseudofruto do caju & $264 \mathrm{~g}$ \\
\hline 3. Vinagre de arroz & $250 \mathrm{~mL}$ \\
\hline 4. Açúcar refinado & $500 \mathrm{~g}$ \\
\hline 5. Sal & $10 \mathrm{~g}$ \\
\hline $\begin{array}{l}\text { 6. Tempero de peixe bonito } \\
\text { 7. Água potável }\end{array}$ & $4 \mathrm{~g}$ \\
\hline \multicolumn{2}{|c|}{ MODO DE PREPARO } \\
\hline $\begin{array}{l}\text { Preparação das Hortaliças } \\
\text { - Higienizar o pepino e o caju com solução de hipoclorito de sódio (200ppm) por } 15 \text { minutos; } \\
\text { - Enxaguar em água potável, drenar e secar em papel absorvente, ambas as hortaliças; } \\
\text { - Cortar o pepino com espessura de 1mm e o caju com 2mm; } \\
\text { - Colocar o pepino e caju em contato com o molho agridoce. }\end{array}$ \\
\hline $\begin{array}{l}\text { Preparação do Molho Agridoce } \\
\text { - Misturar os ingredientes do número 3 a 7 em fogo médio, até dissolver completamente os } \\
\text { sólidos; } \\
\text { - Esfriar até temperatura ambiente, antes de misturar no pepino e o caju. }\end{array}$ \\
\hline
\end{tabular}

Fonte: autoria própria.

\section{Ensaios Microbiológicos E Físico-Químico}

Os ensaios empregaram kits de testes rápidos para detecção de Escherichia coli (Compact Dry EC ${ }^{\circ}$, Staphylococcus coagulase positiva (Compact Dry XSA ) e Salmonella spp. (Compact Dry SL ${ }^{\circ}$, metodologias 
aprovadas pela Codex Alimentarius, APHA (2012) e AOAC (2005), específicos para ensaios microbiológicos para alimentos. Posteriormente, os resultados biológicos do pepino e pseudofruto do caju in natura e no sunomono, foram confrontados com legislações sanitárias que dispõe sobre listas e padrões microbiológicos para alimentos (BRASIL, 2019a e BRASIL, 2019b).

As amostras foram realizadas em duplicata e os resultados expressos em Unidade Formadora de Colônia por grama $\left(\mathrm{UFC}_{\mathrm{g}} \mathrm{g}^{-1}\right)$ para investigação de E.coli e $S$. coagulase positiva e quanto à detecção de Salmonela spp foi expresso em presença ou ausência em $25 \mathrm{~g}$ de amostra.

Foram realizadas análises físico-químico para obter a composição centesimal nas hortaliças in natura e no sunomono, os parâmetros incluíram a determinação da umidade, cinzas, proteína, carboidratos, lipídios totais, $\mathrm{pH}$ e cálculo do valor energético. Os ensaios físico-químicos foram realizados em duplicata e seguiram metodologias da AOAC (2005) e IAL (2008).

\section{RESUlTAdos E DiscUSSÃo}

Com as transformações pelas quais passam a civilização no mundo globalizado, sem fronteiras para o intercâmbio dos alimentos, os costumes e as práticas alimentares de diferentes sociedades se difundem e hibridizam tradições. Como exemplo, temos as influências que sofreu a culinária brasileira, que ao longo de seu processo histórico, incorporou costumes de várias culturas estrangeiras para formação de sua identidade alimentar (CASCUDO, 2004; DORIA, 2014).

As contribuições dos estrangeiros propiciaram que o Brasil se tornasse o terceiro maior produtor mundial de frutas tropicais, com produção anual de 45 milhões de toneladas, das quais 65\% são consumidas internamente e $35 \%$ são destinadas ao mercado externo. Os estrangeiros também influenciaram o mercado brasileiro de hortaliças, diversificando, e na atualidade com volume e garantia de produção em sete espécies: batata, tomate, melancia, alface, cebola, cenoura e pepino. Vale também salientar a importância da agricultura familiar no país, como responsável por mais da metade da produção nacional de hortaliças, participação de forte impacto social e econômico (EMBRAPA, 2017).

Na Figura 1, observamos o porcionamento/fatiamento do pepino in natura (Figura 1a) e do pseudofruto do caju in natura (Figura 1b). Na Figura 1c, a imagem do sunomono de pepino e do caju em conjunto. Para confecção do sunomono, foram utilizados 608gramas de pepino e 264gramas de pedúnculo de caju, que após separação e higienização, foram pesados e resultaram em 571gramas de pepino (1a) e 236 gramas de pseudofruto (1b). Diante desses valores encontrados, estimou-se que a sobras não aproveitáveis no pepino representaram $6,1 \%$ e no pseudofruto do caju foi de $10,61 \%$.

Figura 1 - Imagem de pepino in natura (1a), pseudofruto do caju in natura (2a) e sunomono de pepino

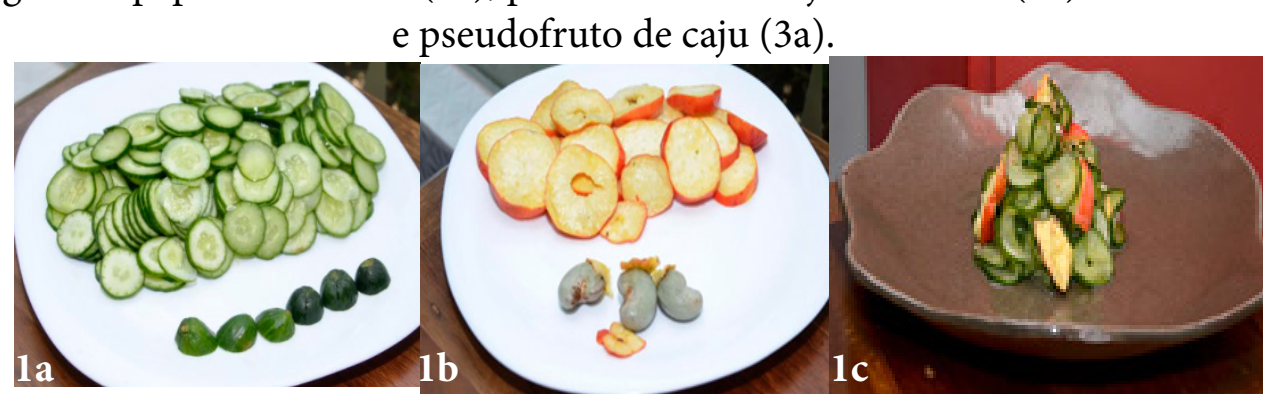

Fonte: autoria própria

Diante dessa oferta de hortaliças e acesso a diferentes técnicas culinárias, foi elaborado sunomono de pepino e pseudofruto do caju, realizando ensaios microbiológicos nas amostras in natura e de sunomono, onde não foi detectado a presença de Escherichia coli, Staphylococcus coagulase positiva e Salmonella 
spp. Esses achados comprovam que a higienização e os sunomonos produzidos estavam em condições higiênico-sanitária satisfatórias para consumo seguro. Segundo Jay (2005), McGee (2011) e Ribeiro et al. (2018), mesmo que houvesse a presença desses microrganismos patogênicos, estes seriam eliminados pela sanitização e a conservação seria beneficiado pelo efeito sinérgico do ácido acético e sacarose nos sunomonos, elevando a acidez e o controle da atividade de água respectivamente, fatores extrínsecos que inibiram a multiplicação de possíveis patógenos ou deteriorantes.

A maioria das hortaliças cresce junto ao solo, sendo passível de apresentar material terrroso, agrotóxicos e microbiota acompanhante, fatores que propiciam a contaminação cruzada. A água contaminada por compostos químicos e microrganismos presentes na produção agrícola, na cadeia de transporte, manipulação e acondicionamento também são fatores que podem aumentar a escala de contaminação. Calcula-se que $20 \%$ das hortaliças e frutas utilizadas para consumo humano, são perdidas como consequência de alterações microbianas, cujos principais agentes causadores são as bactérias, leveduras e bolores (FRANCO, 2012; GERMANO, 2015; MOREIRA et al., 2018).

O sunomono é um exemplo de conservação das hortaliças sazonais, associando o vinagre (ácido acético) com açúcar (sacarose), conhecido como a harmonização do agridoce, técnica culinária modificando a textura, sabor e maior vida útil em relação ao pepino e o pseudofruto de caju in natura (Quadro 1). Em estudo promovido por Padilha e colaboradores (2014), os autores confeccionaram sunomono de palma forrageira, encontrando na técnica da culinária japonesa uma forma de apresentar a Opuntia cochenillifera como uma nova reinvenção gastronômica, uma vez que a palma é considerada um vegetal exclusivamente destinado para alimentação animal no nordeste brasileiro, não tendo o hábito de consumo na forma de alimento pelos humanos, mesmo em períodos de estiagem.

Segundo a Tabela de Composição de Alimentos (TACO, 2011), o pepino cru apresenta a seguinte composição centesimal em cada 100 gramas: 96,8\% de umidade; 0,3g de cinzas; 2,0g de carboidratos; 0,9g de proteínas; traços de lipídeos e valor calórico total de 10,0 Kcal. Esses resultados corroboram com os achados dessa pesquisa, que também encontrou valores próximos para o pepino in natura, conforme observamos na Tabela 1.

Tabela 1 - Composição centesimal do pepino in natura e na forma de sunomono.

\begin{tabular}{ccc}
\hline Parâmetros & Pepino in natura & Sunomono de pepino \\
\hline $\mathrm{pH}$ & 7,02 & 4,78 \\
Umidade & $96,16 \mathrm{~g} / 100 \mathrm{~g}$ & $89,27 \mathrm{~g} / 100 \mathrm{~g}$ \\
Cinzas & $0,58 \mathrm{~g} / 100 \mathrm{~g}$ & $1,04 \mathrm{~g} / 100 \mathrm{~g}$ \\
Carboidratos & $2,32 \mathrm{~g} / 100 \mathrm{~g}$ & $8,68 \mathrm{~g} / 100 \mathrm{~g}$ \\
Proteínas & $0,84 \mathrm{~g} / 100 \mathrm{~g}$ & $0,92 \mathrm{~g} / 100 \mathrm{~g}$ \\
Lipídeos & $0,10 \mathrm{~g} / 100 \mathrm{~g}$ & $0,09 \mathrm{~g} / 100 \mathrm{~g}$ \\
Valor Calórico & $13,54 \mathrm{Kcal} / 100 \mathrm{~g}$ & $39,21 \mathrm{Kcal} / 100 \mathrm{~g}$ \\
\hline
\end{tabular}

Normas analíticas da Association of Official Analytical Chemists e Instituto Adolfo Lutz (AOAC, 2005; IAL, 2008). Resultados expressos em média das duplicatas.

Fonte: autoria própria.

Na Tabela 1, observamos que o $\mathrm{pH}$ encontrado no pepino in natura é neutro $(7,02)$. Segundo Philippi (2014), Domene (2011) e Ornelas (2007), o pepino cru, devido a suas características de alta atividade de água, traços de lipídeos, reduzido valor calórico e $\mathrm{pH}$ na faixa de neutralidade, é indicado para compor dietas de hipertensos, diabéticos, doenças do sistema gástrico e para pessoas que precisam de dietas hipocalóricas para reduzir parâmetros antropométricos junto a grupos de risco nutricional. De acordo 
com Goto (2003) e Carvalho et al. (2013), o pepino além de alto percentual de água livre, é fonte em beta-caroteno, folacina, cálcio, magnésio, potássio, fósforo e selênio.

Na composição centesimal do sunomono de pepino (Tabela 1) foi encontrado aumento do carboidrato total $(8,68 \mathrm{~g} / 100 \mathrm{~g})$ e valor calórico $(39,21 \mathrm{~g} / 100 \mathrm{~g})$, redução do $\mathrm{pH}(4,78)$ quando comparado com o pepino in natura. De acordo com esses resultados, o consumo de sunomono de pepino deve ser realizado com cautela porque o valor calórico é quase 3 (três) vezes superior quando comparado com o pepino in natura e o pH ácido não é recomendado para o comensal que apresenta gastrite, podendo agravar quadros de irritação e lesões da mucosa gástrica. Segundo Zeni et al. (2018), a gastrite crônica é frequente na população idosa, necessitando de maiores cuidados e atenção na rotina dietética junto a esse grupo vulnerável.

$\mathrm{Na}$ cajucultura, uma das grandes dificuldades enfrentadas pelos produtores é a curta vida útil, devido a pericibilidade da estrutura do pedúnculo. A maior parte da produção do pedúnculo do caju apodrece no local da colheita, porque ocorre o rompimento rápido da casca, desencadeando o processo por degradação microbiana. No Brasil houve um esforço governamental para melhoria das técnicas de manuseio e preservação do pseudofruto, para gerar rotas econômicas alternativas de comercialização e consumo (ALVES, MACHADO, QUEIROGA, 2011; LUZ, PINHEIRO, MOUZINHO, 2015). Na Tabela 2, observamos a composição nutricional do pseudofruto do caju in natura e no sunomono, como alternativa de conservação, modificação das características sensoriais e respeito a sazonalidade.

Tabela 2 - Composição centesimal do pseudofruto do caju in natura e no sunomono.

\begin{tabular}{ccc}
\hline Parâmetros & Pseudofruto in natura & Sunomono do pseudo de caju \\
\hline $\mathrm{pH}$ & 4,18 & 4,23 \\
Umidade & $88,28 \mathrm{~g} / 100 \mathrm{~g}$ & $82,77 \mathrm{~g} / 100 \mathrm{~g}$ \\
Cinzas & $0,41 \mathrm{~g} / 100 \mathrm{~g}$ & $0,49 \mathrm{~g} / 100 \mathrm{~g}$ \\
Carboidratos & $9,63 \mathrm{~g} / 100 \mathrm{~g}$ & $14,79 \mathrm{~g} / 100 \mathrm{~g}$ \\
Proteínas & $0,91 \mathrm{~g} / 100 \mathrm{~g}$ & $1,04 \mathrm{~g} / 100 \mathrm{~g}$ \\
Lipídeos & $0,77 \mathrm{~g} / 100 \mathrm{~g}$ & $0,91 \mathrm{~g} / 100 \mathrm{~g}$ \\
Valor Calórico & $49,09 \mathrm{Kcal} / 100 \mathrm{~g}$ & $71,51 \mathrm{Kcal} / 100 \mathrm{~g}$ \\
\hline
\end{tabular}

Normas analíticas da Association of Official Analytical Chemists e Instituto Adolfo Lutz (AOAC, 2005; IAL, 2008). Resultados expressos em média das duplicatas.

Fonte: autoria própria.

Segundo a Tabela de Composição de Alimentos (TACO, 2011), o pseudofruto do caju in natura apresenta a seguinte composição centesimal em cada 100 gramas: $88,1 \%$ de umidade; $0,3 \mathrm{~g}$ de cinzas; 10,3g de carboidratos; 1,0g de proteínas; 0,3g de lipídeos e valor calórico total de 43,0 Kcal. Segundo a Tabela 2, a composição centesimal desse estudo apresentou resultados semelhantes com as informações da Taco e de Alves, Machado e Queiroga (2011). Outra informação nutricional importante quanto ao pedúnculo, que além de ser delicioso, é fonte de Vitamina de C, apresentando cerca de 200mg em cada 100gramas da fruta, concentração superior recomendada pela Organização Mundial de saúde (OMS), que varia de 60 a 100mg/dia, de acordo com a faixa etária e necessidade nutricional (LORENZI, LACERDA, BACHER, 2015; SIZER, WHITNEY, 2003; WANNMACHER, 2006).

Na Tabela 2, observamos que a composição centesimal do sunomono foi superior para carboidratos com $14,79 \mathrm{~g} / 100 \mathrm{~g}$ e valor calórico total de 71,51g/100g, quando comparado com o pseudofruto in natura. De acordo com esses resultados, o consumo de sunomono de pseudofruto de caju deve ser realizado com cuidado porque o valor calórico aumenta de 49,09 kcal em 100g no pseudofruto in natura para 71,51 
kcal para cada $100 \mathrm{~g}$ de sunomono. O pH apresentou a variação de 4,18 a 4,23 o que representou pouca variação de acidez, parâmetro importante para aceitação sensorial junto aos consumidores frequentes do pseudofruto de caju.

Em outra pesquisa promovida por Padilha et al. (2017), que estudou o uso da polpa e albedo da melancia (Citrullus lanatus) in natura, na perspectiva de minimizar perdas de nutrientes de partes comestíveis não convencionais da melancia. A incorporação de ácido acético e sacarose caracterizaram o sabor agridoce, acrescentando atributos sensoriais apreciáveis no sabor, textura e melhores parâmetros de aceitação e possibilidade de comercialização.

As hortaliças são os vegetais que foram o primeiro alimento dos homens, por suas características de composição, devem ser consumidas com o máximo de frescor, suporta pouco tempo de conservação sob refrigeração e alteração física acentuada sob congelamento (ARAÚJO et al., 2011; DOMENE, 2011). No caso do pseudofruto do caju o aproveitamento industrial é inferior a 6\% da produção nacional, por isso é importante o desenvolvimento de processos tecnológicos para aumentar sua vida útil e manter sua qualidade nutricional e funcional, por ser importante fonte de ácido ascórbico da biodiversidade brasileira (ALVES; MACHADO; QUEIROGA, 2011).

A cozinha é espaço de transformação dos alimentos e troca de relações e experiências de caráter pessoal, familiar ou profissional. As energias se comunicam, no caso dos alimentos, sofrendo modificação na composição, textura e aromas. Esse processo de mudança faz parte de um ciclo de energia mais amplo, inclui não apenas a aquisição de ingredientes, formas de preparo, técnicas de cocção e armazenamento correto dos alimentos, mas uma transição similar como na construção da vida, pois buscamos a todo o momento equilíbrio alimentar e sabedoria na promoção e manutenção da saúde (CHUEN, 2000). A UNESCO ressalta os aspectos da washoku quanto a observância na sazonalidade dos alimentos, sustentabilidade e coesão da comunidade local. Os aspectos para determinar o registro como patrimônio mundial do washoku, levou em consideração também que a herança culinária é uma prática cheia de mudanças e atualizações (KOHSAKA, 2017).

O pepino e o pseudofruto do caju representam fonte alimentar importante na dieta humana, entretanto, devido a sua perecibilidade que repercute na vida útil, há a necessidade de constantes buscas na melhor tecnologia ou técnica na preservação dessas hortaliças, o que torna o sunomono uma alternativa viável de consumo e preservação desses grupos de alimento.

\section{REFERÊNCIAS}

ABERC. Associação Brasileira das Empresas de Refeições Coletivas. São Paulo: Aberc. p. 218, 2015.

ALVES, F. M. S.; MACHADO, A. V.; QUEIROGA, K. H. Alimentos produzidos a partir de farinha de caju, obtida por secagem. Revista Verde de Agroecologia e Desenvolvimento Sustentável, v.6, n.3, p. 131-138, 2011.

AOAC.. Association of Official Analytical Chemists. Official methods of analysis of AOAC international. 18st ed. Gaithersburg: AOAC International, 2005. p. 3118, 2005.

APHA. American Public Health Association. Standard Methods for the Examination of Water and Wastewater. 22st ed. APHA: Washington DC, 2012. p. 1496, 2012.

ARAÚJO, W. M. C.; MONTEBEllo, N. P.; BOtelho, R. B. A.; BORGO, L. A. Alquimia dos Alimentos. Brasília: Senac, 2011. 
BRASIL. Ministério da Saúde. Agência Nacional de Vigilância Sanitária (ANVISA). Resolução RDC nº 331 de 23 de dezembro de 2019. Dispõe sobre os padrões microbiológicos de alimentos e sua aplicação. Diário Oficial, Brasília, DF. 26 de dezembro de 2019a.

BRASIL. Ministério da Saúde. Agência Nacional de Vigilância Sanitária (ANVISA). Instrução Normativa $\mathrm{n}^{\circ}$ 60, de 23 de dezembro de 2019. Estabelece as listas de padrões microbiológicos para alimentos. Diário Oficial, Brasília, DF. 26 de dezembro de 2019b.

CARVALHO, A. D. F; AMARO, G. B.; LOPES, J. F.; VILELA, N. J.; MICHEREFF FILHO, M.; ANDRADE, R. A Cultura do Pepino. Brasília, DF: Embrapa Hortaliças. p. 18, 2013.

CASCUDO, L. C. História da Alimentação do Brasil. São Paulo: Editora Global, p. 972, 2014.

CHUEN, L. K. O Feng Shui na Cozinha. São Paulo: Editora Manole, p. 162, 2000.

DOMENE, S. M. A. Técnica Dietética: Teoria e Aplicações. Rio de Janeiro: Guanabara Koogan, p. 350, 2011.

DORIA, C. A. Formação da Culinária Brasileira. São Paulo: Três Estrelas, p. 280, 2014.

EMBRAPA. Empresa Brasileira de Pesquisa Agropecuária. 2017. Disponível em: https://www.embrapa. br/grandes-contribuicoes-para-a-agricultura-brasileira/frutas-e-hortalicas. Acesso em: 21 jun. 2019.

FRANCO, R. M. Agentes Etiológicos de Doenças Alimentares. Niterói: Editora UFF., p. 120, 2012.

FREIRE, J. C. P.; OLIVEIRA JÚNIOR, J. K.; SANTIAGO, C. P. L.; FREIRE, S. C. P.; LIMA, E. O. Estudo Etnobotânico do Cajueiro (Anacardium ocidentale L.): uma Árvore Nativa do Brasil. REVISTA UNINGÁ REVIEW. v. 29, n. 3, p. 123-26, 2017.

FUKUOKA, Y. Cozinha Japonesa. São Paulo: Marco Zero, p. 160, 2008.

FURLAN, H. O; ROCHA, E. M. B.; TAVARES, A. M. C; SILVA, F. R.; GABRI, M. A. S.; SANTANA, M. J. A; BESERRA, T. L.; TAVRES, H. C. 2020. Dieta Vegetariana na Saúde, Meio Ambiente: uma revisão. Estudos em ciências da saúde 2. Organizador Edson da Silva. Ponta Grossa, Paraná: Atena, 2020. p. 55-63.

GERMANO, P. M.; GERMANO, I. S. Higiene e Vigilância Sanitária de Alimentos. São Paulo: Manol, p. 1040, 2015.

GOMES, F. P. Fruticultura brasileira. São Paulo: Nobel, p. 448, 2012.

GOTO, R. Programa brasileiro para a modernização da horticultura: normas de classificação do pepino. São Paulo: CQH/CEAGESP, 2014. Disponível em: http://www.ceagesp.gov.br/wp-content/uploads/2015/07/ pepino.pdf. Acesso em: 10 jan. 2018.

IAL. Instituto Adolfo Lutz. Métodos físico-químicos para análises de alimentos. $4^{\mathrm{a}}$ edição. São Paulo: Instituto Adolfo Lutz, 2008. 1020p. 
Shinohara et al.

JAY, J. M.. Microbiologia de alimentos. Porto Alegre: Artmed, p. 712, 2005.

KAZUKO, E. Culinária Japonesa: receitas fáceis de fazer. São Paulo: Publifolha, p. 216, 2010.

KOHSAKA, R. The myth of washoku: a twisted discourse on the "uniqueness" of national food heritages. Journal of Ethnic Foods, v .4, n. 2, p. 66-71, 2017.

LORENZI, H.; LACERDA, M. T. C.; BACHER, L. B. Frutas no Brasil: Nativas e Exóticas (de consumo in natura). São Paulo: Instituto Plantarum, p. 704, 2015.

LUZ, D., A.; PINHEIRO, R. S.; MOUZINHO, A. M. Determinação de Açúcares do Suco de Caju Comercial por Cromatografia Líquida de Alta Eficiência- CLAE. Revista Higiene Alimentar, v.29, n.250/251, p. 18-23, 2015.

MATOS, E.; QUEIROZ, L. P. P. Árvores para cidades. Salvador: Solisluna, p. 340, 2009.

McGEE, H. Comida e Cozinha: ciência e cultura da culinária. São Paulo: WMFMartins, p. 978, 2011.

MOREIRA, C. C.; COSTA, K. D. S. A.; DUARTE, A. C.; SERRA-FREIRE, N. M.; NORBERG, A. N. Avaliação Microbiológica e Parasitológica de Hortaliças Comercializadas na Baixada Fluminense, Rio de Janeiro. Revista Uniabeu, v.10, n. 26, p. 234-43, 2018.

OLIVEIRA, A. B. B.; SILVA, A R. A.; SIQUEIRA, E. S.; SIQUEIRA FILHO, V. O. Empreendedorismo Rural na Cajucultura: Um Estudo de Caso. HOLOS,v.34, n. 5, p. 116-139, 2018.

ORNELAS, L. H. Técnica Dietética: seleção e preparo de alimentos. São Paulo: Atheneu, 2007. p. $276,2007$.

PADILHA, M. R. F., SANTOS, M. C. G., MATSUMOTO, M., SHINOHARA, N. K. S. \& MELO FILHO, A. B. Revista Nutrição em Pauta ,v.4, n. 23, p. 14-18, 2014.

PADILHA, M. R. F.; SHINOHARA, N. K. S.; MACHADO, J.; MACÊDO, I. M. E.; FERREIRA, E.; MATSUMOTO, M. 2017. Sustainable techniques used in food preparation. Revista Geama, v.3, n. 1, p. 10-16, 2017.

PHILIPPI, S. T. Nutrição e técnica dietética. São Paulo: Manole, p. 400, 2014.

REIS, K. C.; ELIAS, H. H. S.; LIMA, L. C. O.; SILVA, J. D.; PEREIRA, J. Pepino japonês (Cucumis sativus L.) submetido ao tratamento com fécula de mandioca. Ciência e Agrotecnologia, v.30, n.3, p. 487-493, 2006.

RIBEIRO, C.; MATSUMOTO, Y. Culinária Japonesa para Brasileiros. São Paulo: Publifolha, p. 144, 2009.

RIBEIRO, B. D.; PEREIRA, K. S.; NASCIMENTO, R. P.; COELHO, M. A. Z. Microbiologia Industrial: alimentos. Rio de Janeiro: Elsevier, p. 477, 2018.

SIZER, F. \& WHITNEY, E. Nutrição: conceitos e controvérsias. São Paulo: Manole., 2003. 775p.

TACO. Tabela Brasileira de Composição de Alimentos, 2011. Disponível em: http://www.unicamp.br/ 
nepa/taco/contar/taco_4_edicao_ampliada_e_revisada.pdf $>$ arquivo=taco_4_versao_ampliada_e_revisada. pdfAndgt. Acesso em: 09 jun. 2019.

TAN, T. A Cozinha Asiática. Lisboa: Editora Estampa, p. 145, 2005.

UNESCO. Washoku, culturas alimentares tradicionais japonesas, principalmente para a celebração do Ano Novo. Disponível em: https://ich.unesco.org/en/RL/washoku-traditional-dietary-cultures-of-the-japanese-notably-for-the-celebration-of-new-year-00869. Acesso em: 25 jun. 2019.

WANNMACHER, L. Vitamina C: seis problemas em busca de uma solução. Organização Pan-Americana da Saúde - Brasil, v.3, n. 11, p. 1-6, 2006.

YOKOMIZO, G. K. I., HONGYU, K., VIDAL NETO, F. D. C. \& BARROS, L. D. M. Estabilidade e adaptabilidade de clones de cajueiro para características vegetativas e produtivas. Científic@ Multidisciplinary Journal, v. 6, n. 1, p. 55-67, 2019.

ZENI, J.; CHICONATTO, P.; SCHMITT, V.; MAZUR, C. E. Conduta Dietoterápica para Pacientes com Gastrite Crônica e Osteoporose: Relato de Caso. Visão Acadêmica, v. 19, n.4, p. 1-13, 2019. 